\title{
Output Voltage Estimation for Matrix Converter
}

\author{
Bauer, J. \\ Faculty of Electrical Engineering, Department of Electric Drives and Traction \\ Czech Technical University in Prague \\ Technicka 2, Prague, Czech Republic
}

\begin{abstract}
This paper describes influence real semiconductor devices, commutation strategies, modulation period selection and switch on resp. switch off times on output voltage of matrix converter. Methods for decreasing of the influence are mentioned in the paper too.
\end{abstract}

Keywords-Matrix Converter, Indirect Space Vector Modulation, Commutation

\section{INTRODUCTION}

The origin of the Matrix Converter dates back to 1970s. Since that time many different topologies were labeled as "Matrix Converter"[1], [2]. Hence, in this paper, the label Matrix Converter (MC) will be used for symmetrical $3 \times 3$ topology. The matrix converter is in general formed by the array of 9 bidirectional switches, that enable instant connection of arbitrary input phase to arbitrary output terminal. That means that matrix converter doesn't have DC link, which is often bulky. The output voltage is produced by direct switching of voltage from input phases to output phases. To the advantages of the matrix converter compared to common frequency converter belongs: power factor regulation; ability operate in all four quadrants; high voltage regulation dynamics; sinusoidal consumption of input currents; nearly sinusoidal output voltage waveform, with low harmonic content and high efficiency. The main disadvantages include: increased number of semiconductor devices, a complicated regulation algorithm, and output voltage amplitude is limited by $86,6 \%$ voltage amplitude on the input due to the DC link absence[1], [3], [4].

Arrangement of the bidirectional switches is schematically depicted in Fig 1.

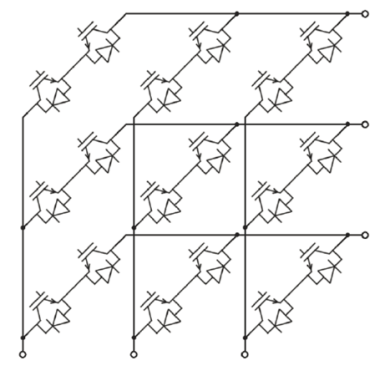

Figure 1. Semiconductor switches matrix arrangement
In general there are various possible configuration of bidirectional switch implementation. It is always combination of IGBT and antiparallel diode. Configuration with common emitter (Fig. 1) belongs to the most spread ones.

\section{MODULATION STRATEGY}

Compared to indirect frequency converter the matrix converter produces the voltage on its output by direct switching of particular suitable voltage from input of the converter. Moreover the absence of the DC link influences naturally behavior of the matrix converter and places some restrictions of switching procedure. Because on the input of the matrix converter is usually filter with capacitor, it can be considered as voltage source, therefore none of the input phases shall be shortcircuited anytime. When the load connected to the output of the converter has inductive character none of the output phases of the converter can be disconnected [2], [5].

With respect to these restrictions several modulation strategies has been developed [5-9]. The most relevant modulation and control strategies for the matrix converter are summarized in [5]. One of them is so called indirect space vector modulation (ISVM) that was proposed by Huber and Borojevic [9]. The ISVM strategy splits the converter into two virtual parts according to the function that they perform. The aim of the converter's input part is to direct required current into the virtual DC link. The required voltage from the virtual DC link is then produced by virtual voltage source inverter (VSI) in same way as common VSI does. The switched voltage vectors are selected from the most suitable space vectors available for both parts (see Fig. 2).
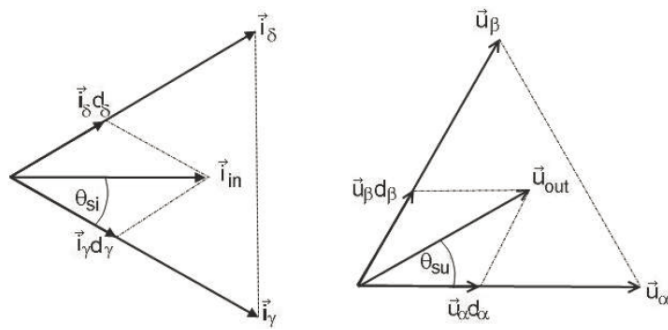

Figure 2. Virtual inverter and virtual rectifier space vectors 
Modulation of the virtual inverter is generated as two nearest active voltage vectors and zero vector. Duty times $d_{\alpha}$ and $d_{\beta}$ correspond to both active vectors. The output voltage vector equation is

$$
\underline{u}_{2}=\underline{u}_{2 \alpha} d_{\alpha}+\underline{u}_{2 \beta} d_{\beta}
$$

The input current reference vector can be generated analogously as voltage reference vector combining two adjacent active current vectors and zero vector. The final duty times can be now obtained as simple fusion of input and output duty times [5], [10].

$$
\begin{gathered}
d_{\alpha \gamma}=m_{I} m_{U} \sin \left(\frac{\pi}{3}-\Theta_{U}\right) \sin \left(\frac{\pi}{3}-\Theta_{I}\right) \\
d_{\alpha \delta}=m_{I} m_{U} \sin \left(\frac{\pi}{3}-\Theta_{U}\right) \sin \left(\Theta_{I}\right) \\
d_{\beta \gamma}=m_{I} m_{U} \sin \left(\Theta_{U}\right) \sin \left(\frac{\pi}{3}-\Theta_{I}\right) \\
d_{\beta \delta}=m_{I} m_{U} \sin \left(\frac{\pi}{3}-\Theta_{U}\right) \sin \left(\Theta_{I}\right)
\end{gathered}
$$

where $\Theta_{\mathrm{U}}$ is angle of required voltage vector in the particular sector and $m_{\mathrm{U}}$ is modulation index of the output voltage. The $\mathrm{d}_{\gamma}$ and $\mathrm{d}_{\delta}$ represents duty times of both active vectors, $\Theta_{1}$ is angle of generated voltage vector within the current sector (Fig. 2) and $m_{\mathrm{I}}$ is modulation index. For the rest of the switching period zero vector is switched on. Different sequences of the duty times can optimize switching of the converter from the point of power losses, harmonics content. Because switching is source of power losses in converter it is good to optimize number of necessary transistor switching. From (2) follows that one switching period is realized by 4 active vectors and one zero vector. The sequence of switching of the vectors can be used as optimization (see Fig. 3). This optimization can be even refined by translation of switching sequences in two following periods (see Fig. 4). [10]

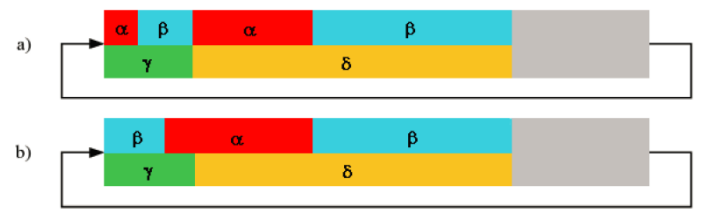

Figure 3. Example of switching sequence optimization a) 8 switching b) 7 switching

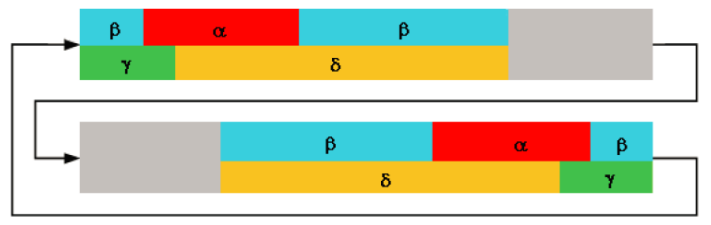

Figure 4. Example of switching sequence optimization by adjacent sequence swapping

\section{INFLUENCE OF THE REAL TRANSISTOR ON OUTPUT VOLTAGE}

The IGBTs that form bidirectional switches are not ideal devices it is necessary to respect several limitations during production of switching patterns
- Maximal switching frequency

- Dead time

- Minimal switching time

All those limitations are known from indirect frequency converter, however because of lack of DC link they should be respected differently for the matrix converter.

\section{A. Maximal Switching Frequency}

For the indirect frequency converter means switching period usually period of PWM generator, during this period is performed one switch on and switch off of the IGBT. For the MC with ISVM strategy is switching period time interval that is required for realization of the whole ISVM sequence. It has been already mentioned that switching sequence can be used for optimization of number of required switching of bidirectional switches.

\section{B. Dead Time}

For the inverter is dead time necessary time delay between switch off of one transistor and switch on of second transistor in one leg. This time delay protects inverter against DC link short circuit. Matrix converter doesn't contain DC link, but it has filter on its input, that usually contain capacitor. Connection of two output phases to one input phase will produce shortcircuit between phases. In Fig. 5 is depicted situation where has bad commutation sequence caused shortcircuit between phases. Therefore dead time should be added into matrix converter commutation strategy too.

Figure 5. Shortcircuit between input phases

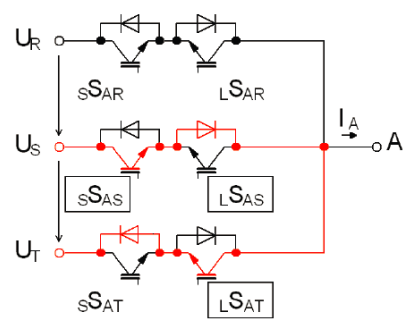

\section{Minimal Switching Times}

IGBT in bidirectional switch doesn't change its impedance instantly. There is required minimal switching time to flood the structure with electrons. This time must be ensured to preform correct switching off procedure. For the common inverter minimal switch on resp. switch off time limit minimal resp. maximal reference for the modulator. When utilizing the indirect space vector modulation the situation is more complicated, because of the bidirectional switches. It means that minimal switching time for the bidirectional switch is time when the whole commutation is finished. For the four step commutation strategy this leads to minimally one switch off time and 3 dead times [11]. This situation is schematically depicted in Fig. 6. Where are shown four steps of commutation process for current flow transfer from phase $\mathrm{R}$ to phase $\mathrm{S}$ [10]. Three bidirectional switches corresponding to the output 
phase A are depicted in Fig. 6 with the gate signals for the transistors. Before the procedure starts $S_{A R I}$ and $S_{A R 2}$ are on and $S_{A R I}$ conducts current. The commutation procedure starts at $t_{1}$ when nonconducting switch $S_{A R 2}$ is switched off. Next step is performed in $t_{2}$ when switch $S_{A S I}$ that conducts in direction of $i_{A}$ in the next phase is switched on. In $t_{3}$ the presently conducting switch $S_{A R I}$ is turned off. The commutation is finished in $t_{4}$ when the non-conducting transistor of the bidirectional switch $S_{A S}$ is switched on. The instant of the current commutation presented in Fig. 6 depends on the polarity of the line to line

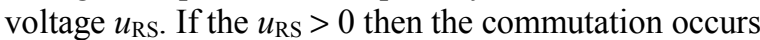
at $t_{3}$ otherwise the commutation occurs at $t_{2}$. When the commutation appears at the $t_{3}$ the turn off of $S_{A R I}$ is hard turn off and other switching are soft, because the positive $u_{\mathrm{RS}}$ is held by non-conducting anti parallel diode of $S_{A R I}$.

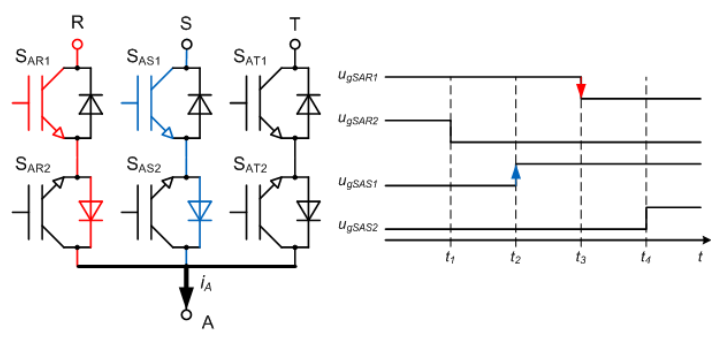

Figure 6. Four step commutation procedure from phase R to phase S

According to (2) 4 active vectors are switched during one modulation period. Minimal switch on resp. off time cause that modulator can't generate arbitrary voltage resp. current vectors. In order to reach the minimum switching time, it is possible to use solution known from the indirect frequency converter required switching shorter than the minimum switching time will be extended. This can be further soften, so that the extension occurs only if the duty cycle is greater than half the minimum switching time. Otherwise the switching is not realized. In both cases respecting of the time minimal switching time introduces inaccuracies in output voltage. This situation is depicted in Fig. 7. Areas where are active minimal switching time correction for the virtual inverter part are depicted in polar chart. The virtual inverter part was driven to switch voltage space vector rotating with frequency $20 \mathrm{~Hz}$ and different modulation indexes. For the legibility Fig. 7 show only corrected voltage vectors, the "normally" switched voltage vectors are neglected.

From the Fig. 7 is obvious that minimal switch on time and dead time influence accuracy of generated voltage close to the boundaries of the sectors, where the switching times are very short. Moreover dead time has to be generated for the zero voltage vector too. The influence of the protection times on the generated voltage vector can be expressed by

$$
u_{2 \max }^{\prime}=u_{2 \max }\left(1-\frac{t_{\min }}{T_{S}}\right)
$$

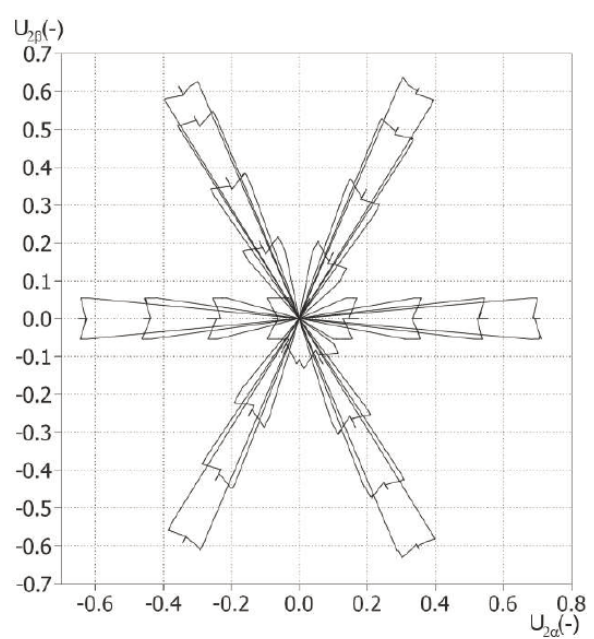

Figure 7. Visualization of minimal switching time correction

Where $t_{\min }$ is minimal switching time for the matrix converter and $T_{\mathrm{s}}$ is switching period. From the (3) is obvious that ratio between minimal switching time and sample time influence the maximum of the output voltage. Dead time for the IGBT used in matrix converter was set to be $t_{\min }=8 \mu \mathrm{s}$, modulation period is $T_{\mathrm{S}}=144 \mu \mathrm{s}$. From (3) follows that theoretical transfer ratio 0,866 will be further reduced to 0,77 . Reduction of the modulation period will increase transfer ratio of the matrix converter, but it will also lead to increase of the generated voltage error. Measurement is shown in Fig. 8.

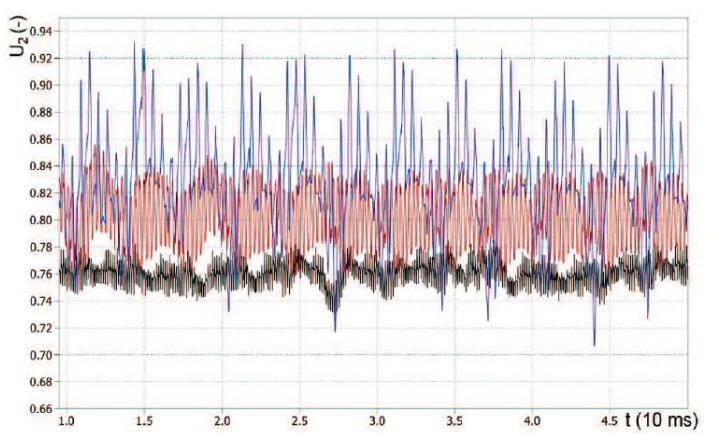

Figure 8. Influence of $t_{\min }$ to $T_{\mathrm{S}}$ ratio on the output voltage of the matrix converter $T_{\mathrm{S}}=144 \mu \mathrm{s}\left(\right.$ black), $T_{\mathrm{S}}=288 \mu \mathrm{s}(\mathrm{red}), T_{\mathrm{S}}=576 \mu \mathrm{s}$ (blue),

\section{Estimation OF THE OUTPUT VOLtAGE}

Accurate information about the output voltage isn't important for the function of the converter itself, but the accuracy is essential for control strategies of the IM fed by the converter. That is why the estimation algorithm for backward calculation of the converter's output voltage was implemented. Based on the knowledge of the knowledge about duty cycles of particular input voltage vectors it can be estimated as 


$$
\begin{gathered}
u_{2 e \alpha}=\frac{u_{\gamma \alpha} \cdot t_{\gamma \alpha}+u_{\delta \alpha} \cdot t_{\delta \alpha}}{T_{S}}+ \\
+\frac{u_{\gamma \beta} \cdot t_{\gamma \beta}+u_{\delta \beta} \cdot t_{\delta \beta}}{T_{S}} \cdot \cos \left(\frac{\pi}{3}\right) \\
u_{2 e \alpha}=\frac{u_{\gamma \beta} \cdot t_{\gamma \beta}+u_{\delta \beta} \cdot t_{\delta \beta}}{T_{S}} \cdot \sin \left(\frac{\pi}{3}\right)
\end{gathered}
$$

where $u_{2 \mathrm{e} \alpha}$ a $u_{2 \mathrm{e}} \beta$ are $\alpha-\beta$ components of the estimated output voltage in given sector, $t_{\gamma \alpha}, t_{\delta \alpha}, t_{\gamma \beta}, t_{\delta \beta}$ are switching times of the given switching vector, $T_{S}$ is switching period, and $\mathrm{u} u_{\gamma \alpha}, u_{\delta \alpha}, u_{\gamma \beta}, u_{\delta \beta}$ are the immediate values of the virtual DC link voltage for given switching combinations.

Estimated value of the output voltage in $\alpha-\beta$ coordinates is in Fig.9.

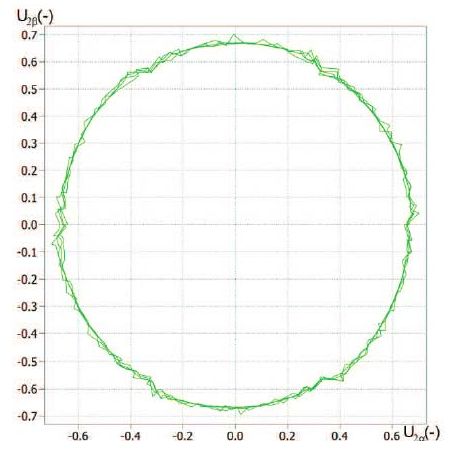

Figure 9. Estimated value of the output voltage of matrix converter

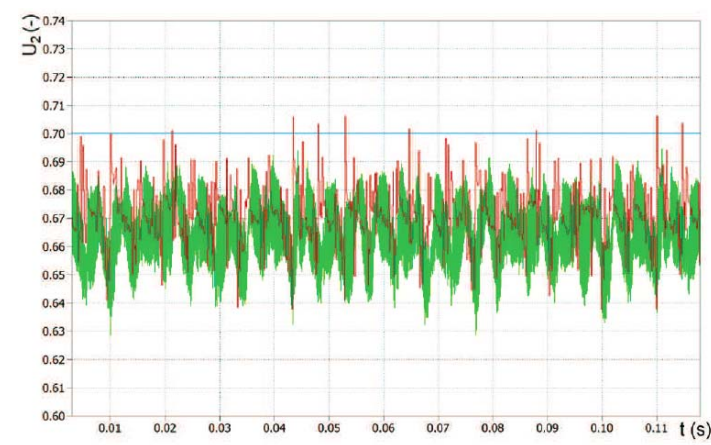

Figure 10. Comparison of reference output voltage (blue), estimated output voltage (red), measured output voltage (green).

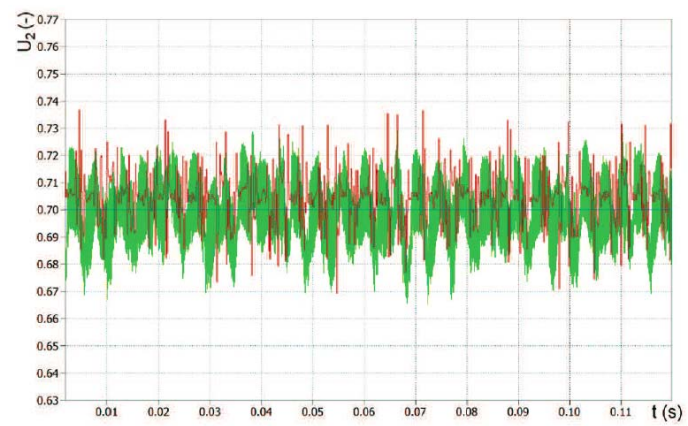

Figure 11. Comparison of reference output voltage (blue), estimated output voltage (red), measured output voltage (green) with implemented commutation influence compensation.
Figs. 10 - 11 show comparison of required value, estimated value and measured value on converter's output. Precision of the estimation can be further increased by compensation of commutation. This can be done by subtracting of commutation time from the active vectors.

\section{CONCLUSION}

The article describes matrix converter topology and indirect space vector modulation strategy used for output voltage synthetization. Influence of real semiconductor devices on the generated output voltage was theoretically and practically evaluated. Methods to neglect influence of the real devices were presented. Even static compensation of commutation influence gives very promising outputs.

\section{ACKNOWLEDGMENT}

This research was supported by Technology Agency of the Czech Republic, grant No. TE02000103.

\section{REFERENCES}

[1] P. W. Wheeler, J. Rodriguez, J. C. Clare, L. Empringham, and A. Weinstein, "Matrix converters: a technology review," in IEEE Trans. on Industrial Electronics, 49(2):276-288, 2002.

[2] S. Fligl, Matrix Converter in Hybrid Drives, PhD thesis, CTU in Prague, Prague, 2006.

[3] S. Fligl, "Contribution to the mathematical description of the matrix converter power electronic topology," in Applied Electronics 2011 International Conference on, 2011.

[4] Lettl J., Fligl S., "Matrix converter control system," in Proceedings of PIERS-05, pp. 395-398, Hangzhou, 2005.

[5] J. Rodriguez, M. Rivera, J. W. Kolar, and P. W. Wheeler, “A review of control and modulation methods for matrix converters," , IEEE Trans. on Industrial Electronics, 59(1):58-70, 2012.

[6] M. Mengoni; L. Zarri; A. Tani; G. Rizzoli; G. Serra; D. Casadei, "Modulation strategies for three-phase AC-DC matrix converters: A comparison", in IEEE Energy Conversion Congress and Exposition (ECCE), 2016

[7] A. Popovici; M. Băbăiţă; P. Papazian, "Synthesis of universal space vector modulator for matrix converters", in 12th IEEE International Symposium on Electronics and Telecommunications (ISETC), 2016

[8] Sandeep J.; Ashok S.; Rijil Ramchand, "Carrier based space vector modulation for Matrix Converters" in 1st International Conference on Power Electronics, Intelligent Control and Energy Systems (ICPEICES), 2016

[9] L. Huber and D. Borojevic, "Space vector modulation with unity input power factor for forced commutated cycloconverters," In Conference Record of the 1991 IEEE Industry Applications Society Annual Meeting, 1991, 1991.

[10] P. Pošta, Modulator for the Matrix Converter, PhD thesis, CTU in Prague, Prague, 2015.

[11] M. Pfeifer and G. Schroder, "New commutation method of a matrix converter," In IEEE International Symposium on Industrial Electronics, pages 1516-1519, 2009. 